\title{
Automated feedback control of subcutaneous glucose concentration in diabetic dogs
}

\author{
K. Rebrin, U. Fischer, T. v. Woedtke, P. Abel and E. Brunstein \\ Central Institute of Diabetes "Gerhardt Katsch", Karlsburg, GDR
}

Summary. The subcutaneous tissue is generally considered as a potential site for the monitoring of intracorporal glucose concentration by means of implanted sensors. We studied the suitability of using the resulting signal from the interstitial glucose concentration as an input in a feedback-controlled system for insulin administration. Miniaturized glucose electrodes (amperometric glucose oxidase sensors for the measurement of hydrogen peroxide) were implanted in insulin-dependent diabetic dogs. The output of these sensors was fed into the controller of a bedside-type artificial $B$ cell. Insulin was infused by the device intravenously on the basis of a proportional-differential algorithm. The glucose patterns were compared to identical experiments where feedback control was accomplished on the basis of paracorporal blood glucose measurement using the same algorithm. Normoglycaemia was restored and maintained in both sets of experiments and oral glucose loads were well compensated for. It is concluded that the apparent subcutaneous glucose concentration is appropriate as an input signal for an artificial $B$ cell.

Key words: Subcutaneous glucose, enzyme electrode, artifícial $B$ cell, diabetic dog.
Closed-loop devices for blood glucose control have been shown to restore and maintain normoglycaemia in Type 1 (insulin-dependent) diabetes [1]. Since the use of these bedside-type machines is limited to short-term studies, efforts are being directed at their miniaturization. This may be achieved by the use of implanted sensors [2]. However, presently available biomaterials do not allow intravascular sensors to function on a longterm basis. An attempt has been made to establish intracorporal glucose monitoring on the basis of subcutaneously implanted glucose sensors [1]. Such electrodes, using immobilized glucose oxidase, were working in both dogs and man over several days [3, 4] and, in man as electron-mediated electrodes by means of ferrocene, over several hours [5]. Thus, implanted subcutaneous glucose electrodes could be employed in combination with telemetric devices to monitor the effectiveness of intracorporal blood glucose control by a portable artificial B cell [6].

Because of the distinct delay between the circulating glucose concentration and the system "implanted sensor plus subcutaneous glucose compartment" [7], the feasibility of automated glucose control on the basis of the output of subcutaneous implanted sensors appeared questionable. Anecdotal studies conducted by Shichiri in non-characterized diabetic patients have, however, suggested the possibility of such control [8]. On this basis therefore, a study was designed to compare the feedback control of glucose concentration in well-characterized chronic Type 1 diabetic dogs either in blood or in subcutaneous tissue under steady and non-steady state conditions. For this, a standard algorithm was used as developed for the i.v. application of insulin on the basis of blood glucose measurement.

\section{Materials and methods}

\section{Animals and experiments}

Glucose-controlled insulin infusions before, during and after oral glucose loads (OGTT, $1 \mathrm{~g} / \mathrm{kg}$ ) were repeatedly performed in four C-peptide negative diabetic dogs [9] of both sexes: age $3.5 \pm 0.3$ years, duration of diabetes $0.75 \pm 0.3$ years, body weight $24.2 \pm 5.9 \mathrm{~kg}$ (means \pm SD). Induction of diabetes, animal keeping and experimental handling have been detailed previously $[10,11]$. For comparison, five non-diabetic control animals of both sexes were observed during OGTT: age $4.2 \pm 2.5$ years, body weight $28.0 \pm 3.7 \mathrm{~kg}$.

The animals were studied $14 \mathrm{~h}$ after the last meal. After skin disinfection, intracutaneous anaesthesia ( $2 \%$ Xylocitin, VEB Jenapharm, Jena, GDR), small incision and blunt subcutaneous tunnelling, a glucose electrode was inserted in the neck [12]. Also, the animals were connected to a self-designed paracorporal blood glucose monitoring system, as usually employed in bedside-type artificial B cells.

The in-situ run-in period of the implanted electrodes was completed between 2 and $4 \mathrm{~h}$ after implantation. Then, the sensor current was adjusted to the actual blood glucose concentration. No recalibration of the sensor signal was performed during the experiment. In the diabetic animals, two sets of experiments were performed in random order at one-week intervals: (1) Feedback control of peripheral venous blood glucose concentration by i.v. insulin infusion, with additional observation of the apparent subcutaneous and plasma glucose 


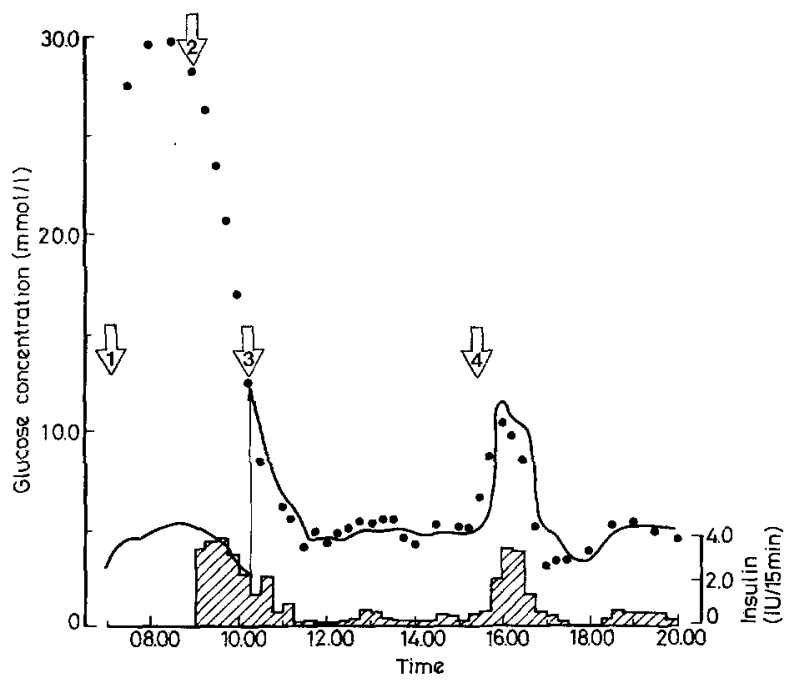

Fig. 1. Individual experimental protocol: feedback control of subcutaneous glucose concentration in a diabetic dog. Arrows: (1) Subcutaneous insertion of glucose sensor. (2) Beginning of glucose-controlled insulin infusion, the plasma glucose concentration (filled circles) is feedback-controlled using the "hand-entry" operating mode of artificial B cell. (3) Adjustment sensor output (continuous line) = apparent subcutaneous glucose concentration to simultaneously measured plasma glucose concentration, continuation of feedback control using these numbers as an input to the controller. (4) Application of an oral glucose load. The insulin doses as summed up over intervals of $15 \mathrm{~min}$ are given in the hatched area

levels. Here, the paracorporal blood glucose monitoring system was connected to the artificial B cell computer [10]. (2) Feedback control of subcutaneous glucose concentration by $i . v$. insulin infusion. The output of the subcutaneously implanted electrodes was fed into the artificial controller. Blood glucose was not monitored in these tests.

The non-diabetic animals were studied under identical conditions with the exception that no insulin was infused. In all experiments the animals were observed over at least $1.5 \mathrm{~h}$ under basal conditions following restoration of normoglycaemia, and for an interval of $4 \mathrm{~h}$ following OGTT. Plasma glucose reference values and insulin concentrations were measured according to established methods [8]. The latter were easily measurable in the diabetic animals also, since they had no anti-insulin antibodies [11]. For better representation, the data as printed out by the artificial B cell at intervals of one min were averaged over 5 or $10 \mathrm{~min}$ respectively.

The original protocol is shown in Figure 1, where feedback control of subcutaneous glucose concentration was applied. The glucose-controlled insulin infusion was initiated on the basis of plasma glucose measurements to restore near-normoglycaemia. These data were fed to the artificial B cell by means of a "hand-entry" operating mode. The subcutaneous glucose sensor was implanted simultaneously. From our experience we noted that it usually takes a run-in period of about $2 \mathrm{~h}$ until stable patterns in sensor output are reached [7, 13]. Therefore, according to experimental protocol, at this empirical time point the senor output was re-set to the numbers of measured plasma glucose concentration by means of adjusting the amplifier. From then on, the controller was fed with the sensor output.

\section{Artificial B cell}

Automated feedback control of glucose concentration was accomplished by a self-designed, laboratory-made bedside-type device. A proportional-differential insulin dosage algorithm was used with the same control constants throughout. These had been previously validated using feedback control by means of peripheral venous glucose measurements and of i. v. insulin administration [10].

\section{Glucose sensors}

Both in diluted blood (paracorporal) and in subcutaneous tissue measurements, Clark-type amperometric sensors for the measurement of hydrogen peroxide resulting from the glucose oxidase reaction (Pt anode, $\mathrm{Ag} / \mathrm{AgCl}$ cathode) were used. The electrodes were layered with immobilized glucose oxidase (GOD, VEB Arzneimittelwerk, Dresden, GDR), a perforated polyethylene membrane (VEB Babychic, Finsterwalde, GDR), and an outer covering membrane of regenerated cellulose (Cuprophane, VEB Geraetewerk, Medingen, GDR). In vitro- and in vivo handling of sensors have been extensively described before $[7,13]$. The glucose sensors had been prepared between 2 and 16 days before the experiments and were stored in $2 \%$ albumin-containing solution. Some of the sensor preparations were repeatedly used as long as there was no mechanical alteration of the sensor membranes. The linear range of calibration slope was $>15 \mathrm{mmol} / \mathrm{l}$. The in vitro characteristics of the sensors were practically identical before and after the implantation experiments (Table 1).

\section{Statistical analysis}

The means $\pm S E M$ of measured values are given. Since normal distribution of these data could not be proved, the Kruskal-Walles test with multiple comparisons according to Conover [14] was employed as a distribution-free procedure to check differences for their significance $(p<0.05)$.

Table 1. In vitro calibration of subcutaneously implanted glucose sensors before and after the experiments ( $n=25$, the average duration of implantation was $8 \mathrm{~h}$ ). No significant difference

\begin{tabular}{|c|c|c|}
\hline & \multicolumn{2}{|c|}{ Implantation } \\
\hline & Before & After \\
\hline$T_{90}(\min )^{a}$ & $1.50 \pm 1.10$ & $1.42 \pm 0.98$ \\
\hline Sensitivity $\left(\mathrm{nA} \cdot \mathrm{mmol}^{-1} \cdot \mathrm{l}\right)$ & $0.70 \pm 0.26$ & $0.66 \pm 0.23$ \\
\hline Residual current $(\mathrm{nA})^{\mathrm{b}}$ & $1.49 \pm 0.84$ & $1.39 \pm 0.93$ \\
\hline
\end{tabular}

a time until $90 \%$ of the final steady state current is reached after switching the sensor from 5 to $10 \mathrm{mmol} / 1$ glucose containing solutions; ${ }^{\mathrm{b}}$ glucose concentration $=0 \mathrm{mmol} / 1$

Table 2. Applied insulin doses in diabetic dogs during glucose-controlled insulin infusion and plasma insulin concentration in diabetic and in normal animals

\begin{tabular}{|c|c|c|c|}
\hline & \multirow{2}{*}{$\begin{array}{l}\text { Normal } \\
\text { dogs }\end{array}$} & \multicolumn{2}{|c|}{ Feedback control of } \\
\hline & & $\begin{array}{l}\text { Circulating } \\
\text { blood glucose }\end{array}$ & $\begin{array}{l}\text { Subcutaneous } \\
\text { tissue glucose }\end{array}$ \\
\hline \multicolumn{4}{|l|}{$\begin{array}{l}\text { Insulin doses } \\
\text { basal }^{\mathrm{a}}\end{array}$} \\
\hline$\left(\mathrm{mU} \cdot \mathrm{kg}^{-1} \cdot \mathrm{min}^{-1}\right)$ & - & $0.60 \pm 0.06$ & $0.68 \pm 0.08$ \\
\hline$\left(\mathrm{mU} \cdot \mathrm{kg}^{-1} \cdot 180 \mathrm{~min}^{-1}\right)$ & & $295.62 \pm 22.16$ & $326.04 \pm 38.80$ \\
\hline \multicolumn{4}{|c|}{ Plasma insulin concentration } \\
\hline basal $^{\mathrm{b}}(\mathrm{nmol} / \mathrm{l})$ & $0.14 \pm 0.07$ & $0.20 \pm 0.01$ & $0.22 \pm 0.03$ \\
\hline $\begin{array}{l}\text { AUC OGTTC } \\
\left(\mathrm{nmol} \cdot 1^{-1} \cdot 180 \mathrm{~min}^{-1}\right)\end{array}$ & $23.08 \pm 3.01$ & $39.79 \pm 3.25^{\mathrm{d}}$ & $46.53 \pm 3.03^{\mathrm{d}}$ \\
\hline
\end{tabular}

a average over $60 \mathrm{~min}$ before oral glucose tolerance test (OGTT);

${ }^{b}$ average of 6 measurements at intervals of $10 \mathrm{~min}$; ${ }^{\mathrm{c}}$ Area under the curve (AUC): immunoreactive insulin response curves during OGTT $0-180 \mathrm{~min}$; ${ }^{\mathrm{d}}$ significant difference $(p<0.05)$ vs normal control animals 


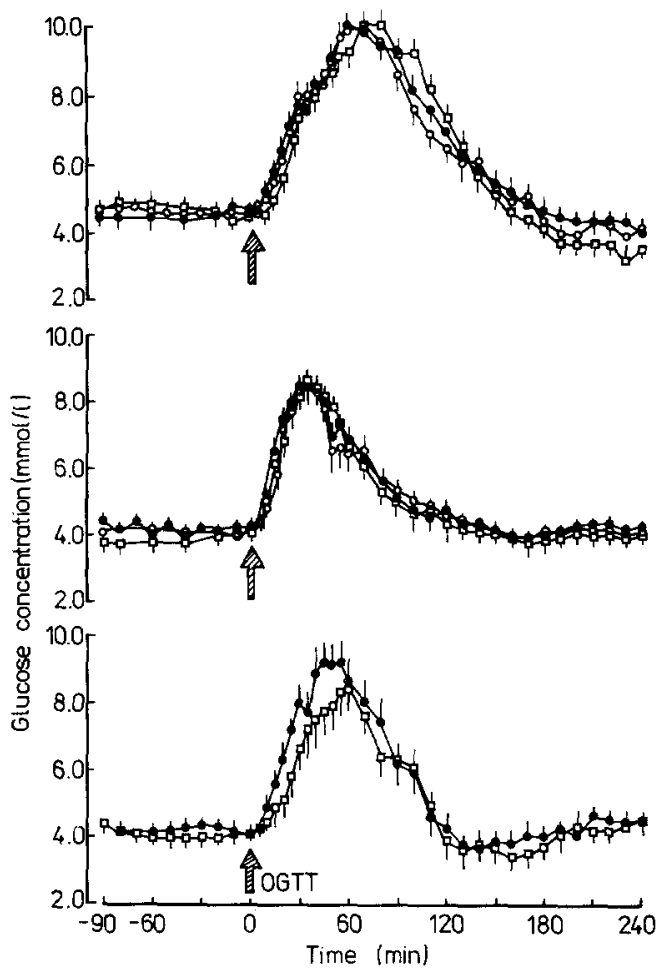

Fig. 2. Concentrations of glucose in plasma (filled circles), blood (open circles), and in subcutaneous tissue (squares) in normal dogs (upper panel, $n=9$ experiments in 5 animals) and in diabetic dogs on feedback control either of glycaemia (middle panel, $n=9$ experiments in 4 animals) or of the apparent subcutaneous glucose concentration (lower panel, $n=7$ experiments in the same 4 animals) before and after oral glucose tolerance test (OGTT). Means \pm SEM

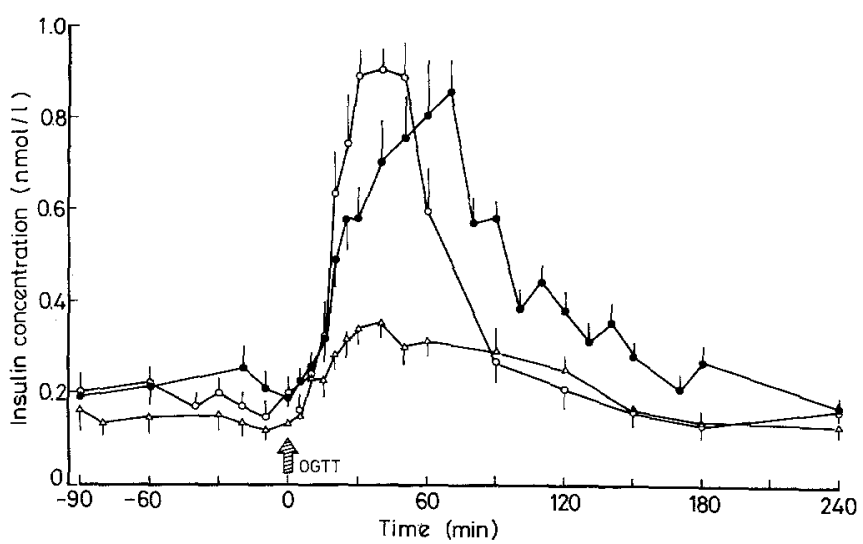

Fig.3. Peripheral venous plasma insulin concentration in normal dogs (triangles) and in diabetic dogs on feedback control either of glycaemia (open circles) or of the apparent subcutaneous glucose concentration (filled circles). Means \pm SEM. Same experiments as in Figure 2

\section{Results}

In the feedback control tests of subcutaneous glucose concentration, stable conditions were achieved both in pre- and post-OGTT basal states, and the glucose load was compensated for without exaggerated hyperglycaemia or oscillations (Fig.2). Also, there were only minor differences in the tests with blood glucose control. The integrated responses of the controlled vari- ables to the glucose loads (areas under the concentration curves) were $262 \pm 37 \mathrm{mmol} / 1 \cdot 180 \mathrm{~min}^{-1}$ in control of subcutaneous glucose and $270 \pm 18 \mathrm{mmol} / \mathrm{l}$. $180 \mathrm{~min}^{-1}$ in control of blood glucose concentration (not significantly different). However, there were slight differences in the kinetics: maximum increases were seen after $58 \pm 5 \mathrm{~min}$ in tissue glucose control and after $38 \pm 3 \mathrm{~min}$ in blood glucose control $(p<0.05)$.

It should be noted that on the basis of the employed calibration regime, the apparent glucose concentrations were generally almost identical in plasma, circulating blood and subcutaneous tissue. However, there was sometimes a slight difference when glycaemia rose quickly but the slowly moving apparent tissue glucose concentration acted as a control (Fig. 2, bottom). Accordingly, both the infused insulin doses and the plasma insulin concentrations were comparable between these two sets of experiments in the diabetic animals (Table 2, Fig. 3).

There was, however, a remarkable difference between these tests and the observation in non-diabetic animals where glycaemia peaked distinctly later $(63 \pm 5 \mathrm{~min})$ and the restoration of normoglycaemia was slower (Fig.2, top). This resulted in a glycaemic response area of $527 \pm 74 \mathrm{mmol} / 1 \cdot 180 \mathrm{~min}^{-1}(p<0.05)$. Again, it should be noted that the glucose concentrations were approximately identical in all three compartments analysed.

The higher integrated blood glucose responses in the control animals were accompanied by a significantly $(p<0.05)$ smaller increase in the peripheral venous plasma insulin concentration (Fig. 3, Table 2).

Finally, the relatively high failure rate of subcutaneous glucose monitoring needs to be mentioned. Beside the data demonstrated, we performed another set of 10 experiments where no stable normoglycaemic intracorporal glucose control was achieved using subcutaneous monitoring. In 4 of these tests the setting of sensor output at the assumed end of the in-situ run-in period proved incorrect, thus causing a permanently insufficient insulin dosage which resulted in hyperglycaemia. In the remaining 6 experiments there was a continuous loss in sensitivity of the implanted sensor until zero current was reached between 4 and $6 \mathrm{~h}$ later causing termination of the experiment. Our major concern is how to reduce the failure rate of implanted sensors. Remarkably, in none of these cases was any difference observed in the in vitro calibration characteristics which were obtained both before and after in vivo residence of the sensor. Also, each of the sensor preparations could be re-used in situ as long as the membrane covering was not mechanically damaged. This points strongly to the problem of tissue reaction to bioincompatible material at the sensor surface.

\section{Discussion}

In a previous study, it was shown that under steady state conditions the overall glucose concentrations in circulating blood and subcutaneous interstitial fluid are ap- 
proximately identical [7]. Therefore, the current output of the implanted sensors was adjusted according to the simultaneous plasma glucose estimates. It remained stable throughout the experiments reported here, no insitu recalibration was necessary. In vitro calibrations of the removed sensors revealed essentially the same characteristics (Table 1) as before implantation.

There is a total delay between glycaemia and apparent sensor-recorded subcutaneous glucose concentration of approximately $5 \mathrm{~min}$ which includes the time constants of both sensor function and subcutaneous fluid [7]. It has, however, been predicted from the comparison between blood glucose control data by means of a miniaturized artificial B cell and simultaneous subcutaneous tissue glucose recordings by means of implanted electrodes $[3,4,6]$ that reasonable automated feedback control might be possible on the basis of such sensor outputs. Thus, our data show that in fact stable patterns are achieved both in tissue and in blood when in diabetic animals automated feedback control is utilized in this way. This applies both to basal conditions and to alterations in glycaemia as during an OGTT.

It should be noted, however, that this observation made in diabetic dogs is accompanied by a distinct peripheral hyperinsulinaemia as compared to the nondiabetic dogs. Obviously, this is not only due to the post-hepatic route of insulin administration [15], but also to the fact that the proportional-differential insulin dosage algorithm used was elaborated using venous blood glucose data of an average diabetic dog population [10]. Since an oral glucose load is metabolized to a large extent in extrahepatic tissues [16], it is assumed that the degree of peripheral hyperinsulinaemia obtained with this algorithm was able to reduce the overall glycaemic response to OGTT in these diabetic animals in relation to the non-diabetic control animals. Also, it is known that due to the time delay of the glucose sensor there is a delay in the initial response of insulin dosage to the elevated blood glucose concentration. Thus, a higher rate of insulin infusion is necessary to compensate for the fast-rising glucose level in this situation [17].

Therefore, the adaptation of the algorithm both to the needs of an individual patient and to the kinetic properties of the controlled glucose compartment including the sensing system appears necessary. The feasability of such adaptive steps has previously been shown [18].

Taken together, the data demonstrated show the principle effectiveness of feedback control of intracorporal glucose metabolism using the signal of subcutaneously implanted electrochemical glucose sensors as an input into the artificial B cell. Future work is to be directed at improving the biostability of such sensors.

Acknowledgements. This work was part of the research project HFR M28 of the Ministry of Health of the German Democratic Republic. The skilful technical assistance of Miss C.Prehl and Mrs. H. Schroeder is gratefully acknowledged.

\section{References}

1. Pfeiffer EF (1987) On the way to the automated (blood) glucose regulation in diabetic dogs: the dark past, the grey present and the rosy future. Diabetologia 30: 50-65

2. Turner APF, Pickup JC (1985) Diabetes mellitus: biosensors for research and management. Biosensors 1: 85-115

3. Shichiri M, Kawamori R, Goriya Y, Yamasaki Y, Nomura M, Hakui N, Abe H (1983) Glycaemic control in pancreatectomized dogs with a wearable artificial endocrine pancreas. Diabetologia 24: $179-184$

4. Shichiri M, Kawamori R, Hakui N, Asakawa N, Yamasaki Y, Abe H (1984) The development of wearable-type artificial endocrine pancreas and its usefulness in glycaemic control of human diabetes mellitus. Biomed Biochem Acta 43: 561-568

5. Matthews DR, Bown E, Beck TW, Plotkin E, Lock L, Gosden E, Wickham M (1988) An amperometric needle-type glucose sensor tested in rats and man. Diab Med 5: 248-252

6. Shichiri M, Askawa N, Yamasaki Y, Kawamori R, Abe H (1986) Telemetry glucose monitoring device with needle-type glucose sensor: A useful tool for blood glucose monitoring in diabetic individuals. Diabetes Care 9: 298-301

7. Fischer U, Ertle R, Abel P, Rebrin K, Brunstein E, Hahn v. Dorsche H, Freyse EJ (1987) Assessment of subcutaneous glucose concentration: validation of the wick technique as a reference for implanted electrochemical sensors in normal and diabetic dogs. Diabetologia 30: $940-945$

8. Shichiri M, Kawamori R, Hakui N, Yamasaki Y, Abe H (1984) Closed-loop glycemic control with a wearable artificial endocrine pancreas: variations in daily insulin requirements to glycemic response. Diabetes 33: 1200-1202 .

9. Fischer U, Besch W, Freyse EJ (1985) Canine C-peptide for characterization of experimental diabetes in dogs. Endocrine Exp 19: 139-145

10. Fischer U, Jutzi E, Bombor H, Freyse EJ, Salzsieder E, Albrecht G, Besch W, Bruns W (1980) Assessment of an algorithm for the artificial B-cell using the normal insulin glucose relationship in diabetic dogs and man. Diabetologia 18: 97-107

11. Freyse EJ, Hahn v. Dorsche H, Fischer U (1982) Low dose streptozotocin diabetes after partial pancreatectomy in dogs. Histological findings in a new type of experimental diabetes. Acta Biol Med Germ 41: 1203-1210

12. Fischer U, Abel P (1982) A membrane combination for implantable glucose sensor measurements in undiluted biological fluids. Trans Am Soc Artif Intern Organs XXVIII: 245-248

13. Abel P, Mueller A, Fischer U (1984) Experience with an implantable glucose sensor as a prerequisite of an artificial beta cell. Biomed Biochem Acta 43: 577-584

14. Lienert GA (1975) Verteilungsfreie Methoden in der Biostatistik, 2. Aufl. Anton Hain, Meisenheim

15. Horwitz DL (1979) Insulin responses to mixed meals: comparison of an artificial beta cell and normal beta cells. Horm Metab Res [Suppl] 8: 68-71

16. Radziuk J, McDonald TJ, Rubenstein D, Dupre J (1978) Initial splanchnic extraction if ingested glucose in normal man. Metabolism 27: 657-669

17. Sorensen JT, Clark KC, Hillman RS, Soeldner JS (1982) Use of a physiologic pharmacokinetic model of glucose homeostasis for assessment of performance requirements for improved insulin therapies. Diabetes Care 5: 148-157

18. Salzsieder E, Albrecht G, Jutzi E, Fischer U (1984) Estimation of individually adapted control parameters for an artificial beta cell. Biomed Biochim Acta 43: 585-596

Received: 31 October 1988

and in revised form: 11 May 1989

Dipl.-Med. K. Rebrin

Zentralinstitut für Diabetes "Gerhardt Katsch"

DDR-2201 Karlsburg

GDR 